\title{
A Case of Pigmented Bowen's Disease
}

\author{
Jung Woo Lee, M.D., Jae Hur, M.D., Kwang Yeoll Yeo, M.D., Hee Joon Yu, M.D., \\ Joung Soo Kim, M.D. \\ Department of Dermatology, Hanyang University Guri Hospital, Hanyang University College of Medicine, Guri, Korea
}

Pigmented Bowen's disease is characterized by increased melanin pigment in the epidermis or papillary dermis, in addition to the typical findings of Bowen's disease. This disorder has been infrequently reported and it represents less than $2 \%$ of all cases of Bowen's disease. Thus far, there has been only 1 case of pigmented Bowen's disease on the umbilicus in the medical literature, and no such case has been reported in Korea. Pigmented Bowen's disease develops on sun-exposed areas of the face and neck, as well as sun-unexposed areas like the trunk, extremities, perianal area and umbilcus. A 36-year-old man presented with a 9-month history of solitary dark brown slithery or wavy plaque with a verrucous surface on the umbilicus, and the lesion measured 1 $x 2 \mathrm{~cm}$ in size. The histopathologic findings showed hyperkeratosis, parakeratosis and atypical keratinocytes disorderly arranged throughout the epidermis. Increased melanin pigment was noted in the basal layer of the epidermis. From these findings, we diagnosed this lesion as pigmented Bowen's disease. (Ann Dermatol 21(2) $197 \sim 199,2009)$

\section{-Keywords-}

Bowen's disease, Pigmented, Umbilicus

\section{INTRODUCTION}

Bowen's disease is intraepidermal squamous cell carcinoma (carcinoma in situ) and it has the potential to progress to invasive carcinoma ${ }^{1-7}$. It is characterized by slowly growing, sharply demarcated, erythematous plaques that have a scaly or crusted surface ${ }^{1,6}$. Sunlight and chronic arsenic exposure are well-known favorable factors to devel-

Received July 23, 2008, Accepted for publication November 25, 2008

Reprint request to: Joung Soo Kim, M.D., Department of Dermatology, Hanyang University Guri Hospital, 249-1, Gyomun-dong, Guri 471-701, Korea. Tel: 82-31-560-2285, Fax: 82-31-557-4872, E-mail: tuentuen@hanyang.ac.kr op this lesion ${ }^{1-3}$.

Pigmented Bowen's disease is characterized by increased melanin pigment in the epidermis or papillary dermis, in addition to the typical findings of Bowen's disease. It is an uncommon malady and it represents less than $2 \%$ of all the cases of Bowen's disease ${ }^{3}$. We report here on a case of pigmented Bowen's disease with an unusual presentation on the umbilicus of a 36-year-old man.

\section{CASE REPORT}

A 36-year-old man presented with a 9-month history of a gradually enlarging solitary dark brown plaque. The lesion had enlarging after it had suffered a wound and it was forming a mass. His past medical history was unremarkable. The patient had no history of sunburn, chronic arsenical ambient exposure or arsenic administration for medical treatments. On the physical examination, there was a solitary dark brown, well-defined slithery or wavy plaque with a verrucous surface with mild scale on his umbilicus and the plaque measured $1 \times 2 \mathrm{~cm}$ in size (Fig. 1). Histologic examination showed hyperkeratosis, parakeratosis and atypical keratinocytes arranged in a disorderly fashion throughout the epidermis. Increased melanin pigment was noted in the basal layer of the epidermis (Fig. 2). The histologic features were consistent with pigmented Bowen's disease. Our patient was referred to the Department of Plastic Surgery in our hospital and the plaque was removed by wide resection. There has been no evidence of recurrence after 18 months of follow-up.

\section{DISCUSSION}

Pigmented Bowen's disease is an unusual form of squamous cell carcinoma in situ. According to Ragi et $\mathrm{al}^{3}$, the pigmented variant represented $1.7 \%$ (7 cases) of the 420 collected cases of cutaneous Bowen's disease. Thus far, there has been only 1 case of pigmented Bowen's disease 

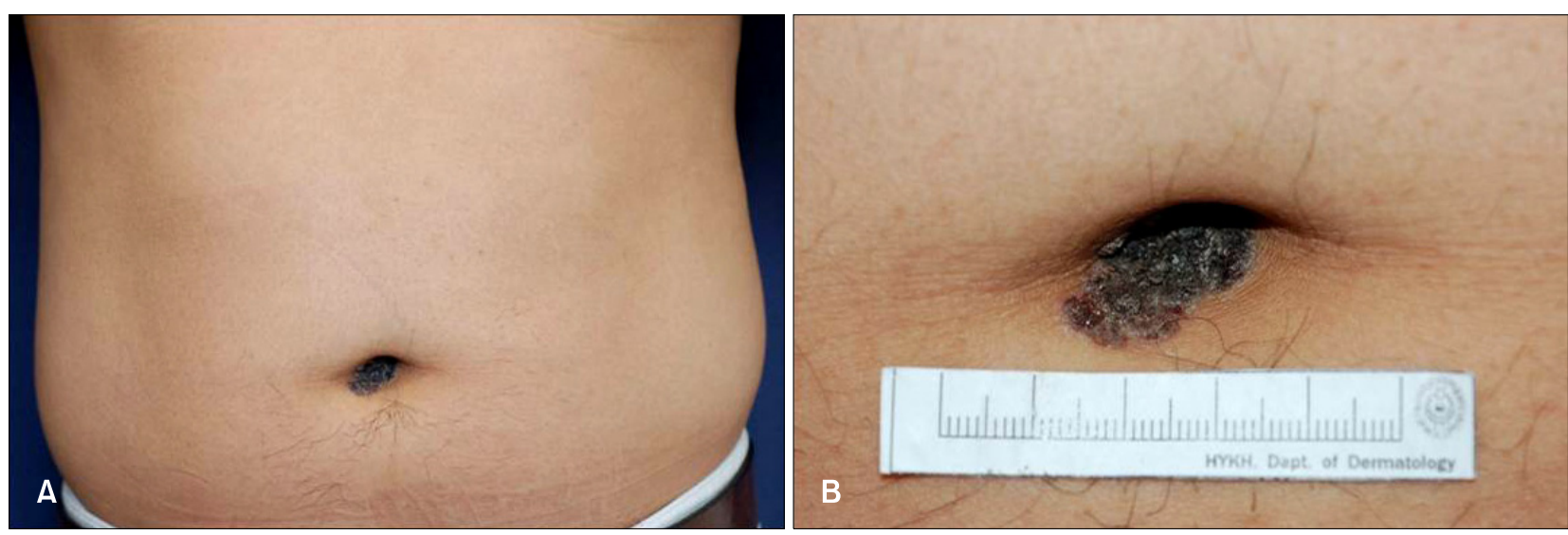

Fig. 1. (A) Solitary black colored verrucous scaly plaque on the umbilicus. (B) The characteristic, slithery or wavy appearance of the lesion was observed on close view.
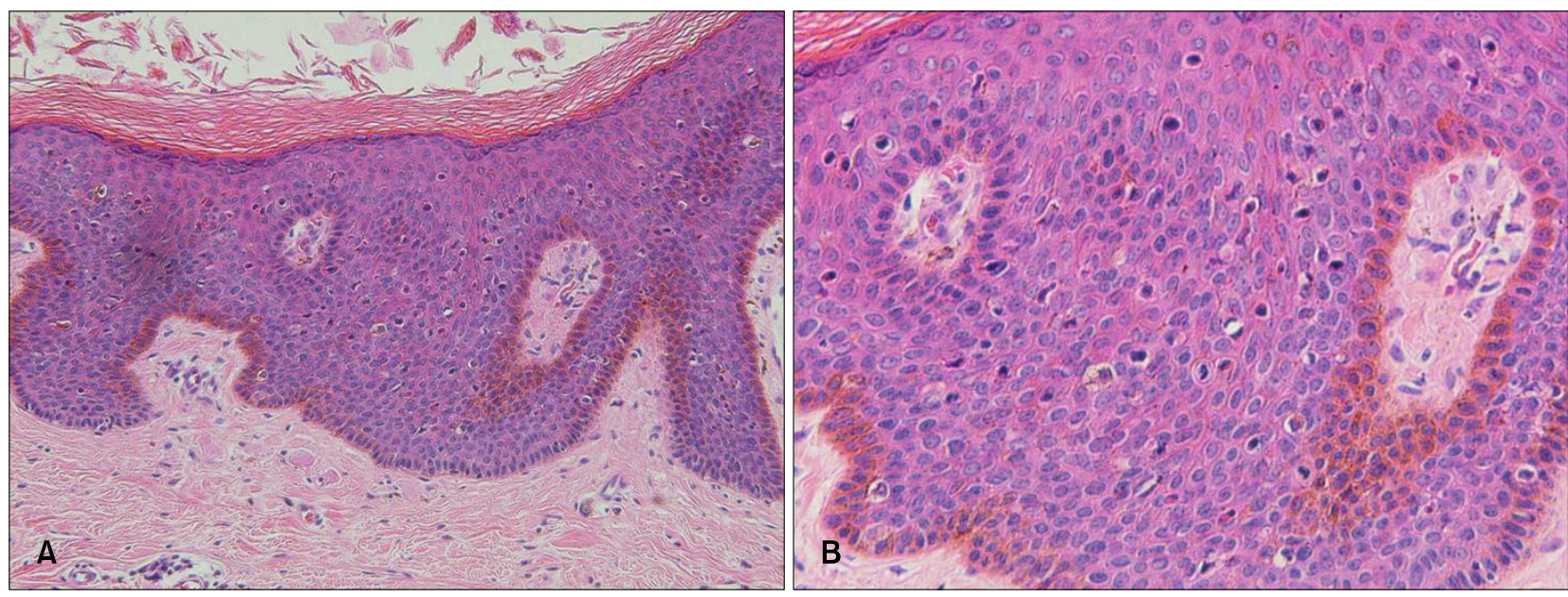

Fig. 2. (A) The epidermis showed full-thickness involvement by atypical keratinocytes with hyperkeratosis, acanthosis, and increased melanin pigmentation (H\&E, x200). (B) Large, round and hyperchromatic nuclei with mitoses were contained within the dyskeratotic cells $(\mathrm{H} \& \mathrm{E}, \mathrm{x} 400)$.

on the umbilicus in the literature ${ }^{1}$, and no such cases have been reported in Korea. This type of lesion commonly presents as a hyperpigmented, sharply marginated plaque with a surface that may be velvety, verrucous or flat, and it is generally asymptomatic ${ }^{4-6}$. Scaling and erosions may be present as well ${ }^{4,7}$. In our patient, the characteristic feature of lesion was a slithery or wavy appearance, and it was nearly the same shape as the previous reported case of pigmented Bowen's disease on the umbilicus ${ }^{1}$. We think some factors like gravity or repetitive, downward scratching motion may have had an influence on these characteristic features, but the reason for this appearance was not revealed in the literature.

Sunlight and chronic arsenic exposure are well-known favorable factors for incurring Bowen's disease $\mathrm{B}^{4-6}$, and this included the pigmented variant. Several other factors such as viral infection, trauma, and radiation have been described as possible etiologic factors ${ }^{2}$. Since the umbilicus is not a sun-exposed area as it is usually protected by clothes, we think that sunlight wasn't an important factor for our patient. Also, our patient had no history of chronic arsenic intoxication, virus infection, trauma or exposure to radiation.

Histologically, pigmented Bowen's disease generally shows epidermal dysplasia with abnormal keratinization $^{1-4}$. The dermis shows no invasion of tumor cells and it sometimes contains a dense infiltrate of lymphocytes or histiocytes. There are characteristically abundant melanin-rich cells in the basal layer. Significant quantities of melanin may be found within the epidermal cells of the basal layer, within the dermal melanophages or within the melanocytes in the affected epithelium ${ }^{1-3}$. For our patient, 
histologic examination revealed full-thickness involvement of the epidermis by atypical keratinocytes. There was acanthosis with thickening of the rete ridge, overlying parakeratosis and hyperkeratosis. Also, abundant melanin pigments were observed in the basal layer of the epidermis.

The mechanism of pigmentation in this disease has not yet been fully discovered. It has been suggested that the neoplastic cells may produce specific factors or cytokines that induce the proliferation of melanocytes and stimulate melanin production ${ }^{2,4}$. Another proposed theory is that the hyperpigmentation of anogenital Bowen's disease might be secondary to elevated temperature or it is simply an extension of the hyperpigmentation that is naturally found in the anogenital area ${ }^{4}$. There are also some reports stating that pigmented Bowen's disease arises from seborrheic keratosis. This suggests the possibility that more than one mechanism may exist ${ }^{4}$.

The differential diagnosis of the solitary type of pigmented Bowen's disease includes seborrheic keratosis, actinic keratosis, pigmented basal cell carcinoma, melanocytic nevus, superficial spreading melanoma and bowenoid papulosis $^{4,8}$. These diseases can be differentiated on the basis of their clinical features and histopathological findings ${ }^{8}$.

Since the presence of additional pigment does not alter the metastatic potential of Bowen's disease, the principles governing the treatment of nonpigmented Bowen's disease are applicable to the pigmented varity ${ }^{4}$. The treatments include surgical operation (standard excision and Mohs micrographic surgery), topical 5-fluorouracil, topical imiquimod, cryotherapy, curettage and electrocautery, radiotherapy, laser ablation (carbondioxide, argon and neodymium:yttrium-aluminumgarnet) and photodynamic therapy (PDT) ${ }^{9-11}$. No single treatment is correct for all forms of pigmented Bowen's disease, but the surgical modalities seem to provide the best treatment with the highest cure rate $^{11}$. Standard excision was performed for our patient, and there has been no evidence of recurrence at the 18-month follow-up.
In conclusion, we clinically experienced a case of pigmented Bowen's disease arising on the umbilicus, and this is the first such case in Korea. Physicians should consider pigmented Bowen's disease in the differential diagnosis of pigmented skin lesions.

\section{REFERENCES}

1. Papageorgiou PP, Koumarianou AA, Chu AC. Pigmented Bowen's disease. Br J Dermatol 1998;138:515-518.

2. Firooz A, Farsi N, Rashighi-Firoozabadi M, Gorouhi F. Pigmented Bowen's disease of the finger mimicking malignant melanoma. Arch Iran Med 2007;10:255-257.

3. Ragi G, Turner MS, Klein LE, Stoll HL Jr. Pigmented Bowen's disease and review of 420 Bowen's disease lesions. J Dermatol Surg Oncol 1988;14:765-769.

4. Krishnan R, Lewis A, Orengo IF, Rosen T. Pigmented Bowen's disease (squamous cell carcinoma in situ): a mimic of malignant melanoma. Dermatol Surg 2001;27:673-674.

5. Stante M, de Giorgi V, Massi D, Chiarugi A, Carli P. Pigmented Bowen's disease mimicking cutaneous melanoma: clinical and dermoscopic aspects. Dermatol Surg 2004;30: 541-544.

6. Saxena A, Kasper DA, Campanelli CD, Lee JB, Humphreys TR, Webster GF. Pigmented Bowen's disease clinically mimicking melanoma of the nail. Dermatol Surg 2006;32: 1522-1525.

7. Hernandez-Gil J, Fernandez-Pugnaire MA, Serrano-Falcon C, Serrano-Ortega S. Clinical and dermoscopic features of pigmented Bowen disease. Actas Dermosifiliogr 2008;99:419420.

8. Wagner RF Jr, Grande DJ. Solitary pigmented Bowen's disease of the scrotum. J Dermatol Surg Oncol 1986;12: 1114-1115.

9. Leibovitch I, Huilgol SC, Selva D, Richards S, Paver R. Cutaneous squamous carcinoma in situ (Bowen's disease): treatment with Mohs micrographic surgery. J Am Acad Dermatol 2005;52:997-1002.

10. Cox NH, Eedy DJ, Morton CA. Guidelines for management of Bowen's disease. British Association of Dermatologists. $\mathrm{Br}$ J Dermatol 1999;141:633-641.

11. Moreno G, Chia AL, Lim A, Shumack S. Therapeutic options for Bowen's disease. Australas J Dermatol 2007;48:1-10. 